\title{
Design and Vibration Analysis for Shaft with Gear Mountings using Finite Element Analysis
}

\author{
Prof. Swapnil J. Patil ${ }^{1}$, Mr. Vipin B. Singh ${ }^{2}$, Mr. Amit M. Pawar ${ }^{3}$. \\ Asst. Prof, Mechanical Engineering Dept, AGTI'S, Dr. Daulatrao Aher College of Engineering, Karad, India ${ }^{1}$ \\ UG Student, Mechanical Engineering Dept, AGTI'S, Dr. Daulatrao Aher College of Engineering, Karad, India ${ }^{2}$
}

\begin{abstract}
This paper contains the study about design and vibration analysis for automobile gearbox element shaft with gear using Finite Element Analysis (FEA). Analysis include the study of equivalent stress and displacement response of the component. The three- dimensional finite element model is constructed in ANSYS. The model is meshed and the boundary conditions with external loads are applied in ANSYS workbench. With the help of ANSYS software we find out the total deformation, equivalent stress which is response for noise and vibration of shaft with gear mounting.
\end{abstract}

Keywords: Shaft and Gear Design, Noise and Vibration, Finite Element Analysis, ANSYS Software.

\section{INTRODUCTION}

Every material structure containing individual mass and maximum stress that a gear tooth is subjected to, under a stiffness distribution is disposed to vibrate and vibration is specified loading. To prevent from failure Analysis is a annoying day-to-day problem in design and production carried on gears[2]. The gears were completely strict and of the machinery or mechanical element. The automobile no geometrical errors or modifications were present, the gearbox is a device which is used to transmit the power gears would transmit the rotational motion perfectly, from one shaft to the other shaft with the help of shaft and which means that a constant speed at the input shaft would gear. Efficiency of the device is one of the important result in a constant speed at the output shaft. The parameter. Gearbox casing is the shell (metal casing) in assumption of no friction leads to that the gears would which a train of gears is mount on the shaft. From the transmit the torque perfectly, which means that a constant movement of the gear it will produce the vibration to the torque at the input shaft would result in a constant torque gearbox casing[4]. The function of gear box casing is to at the output shaft. No force variations would exist and protect and provide a platform for gear transmission. It hence no vibrations and no sound (noise) could be created. also provides supports for moving parts and protection Of course, in reality, there are geometrical errors, from outside environment. It also acts as fluid tight deflections and friction present, and accordingly, gears container which holds the lubricant that bathes the gear some- times create noise and vibration to such an extent box parts. Parts such as gears, shafts, pinion shafts, that it becomes a problem and also reduce life of bearings, oil seals etc. These make the gear box housing component[7].

an essential component in engine of automobile. The gear Numbers of methods are available for the design housing is in the vicinity of the gear box and engine. optimization of structural system or mechanical element Hence will get subjected to vibrations so it becomes and these methods is based on mathematical programming necessary to evaluate the response of gear housing to such technique and optimally designed. Using ANSYS software vibrations and also to find out there natural frequency[1]. which is based on the FEM[8]. ANSYS software is used to Most of the times noise and vibration becomes the major modelling, solving and involves viewing of data files problem of system. The conventional gear box gives us the required power and speed ratio but, they require the proper materials and design geometry for their working. Also they possess large number of parts and become bulky. In some applications, the material and dimensions is the important factor while designing the device[5].

Shaft and gear is the most important part in gearbox of automobile. On shaft different gears are mounted to transmit power from input shaft to output shaft with different speed ratio. If specific r.p.m. matches with critical speed which is nearer to first bending natural frequency of shaft will generate excessive vibrations due to resonance[3].The gears generally fail when tooth stress exceed the safe limit. It is essential to determine the generated by the software during the solution phase of automobile gearbox element such as shaft with gear mounting.

\section{PROBLEM DEFINITION}

Gearbox housing walls and other elastic structures is very important for the noise and vibration emitted by systems into the surroundings. The noise emitted into the surroundings by the gearbox is mostly the consequence of natural fluctuation of the housing and shaft and gears may be mistuned by mesh stiffness variation, manufacturing defect and assembling errors[6]. It is also compulsory to methodically study natural frequency and vibration mode 
IARJSET

International Advanced Research Journal in Science, Engineering and Technology

National Conference on Design, Manufacturing, Energy \& Thermal Engineering (NCDMETE-2017)

AGTI's Dr. Daulatrao Aher College Engineering, Vidyanagar Extension, Karad

Vol. 4, Special Issue 1, January 2017

sensitivities and their veering characters to identify the 2. Bending and torsional moment:

parameters critical to vibration of shaft with gears in gearbox. In the gearbox element like shaft with gear mounting according to their geometry errors, unsuitable material selection, deflection and friction present, and sometime applied force and boundary condition create noise and vibration and also reduce life of component.

\section{III.THEORETICAL DESIGN}

1) Design of shaft: Using ASME code for shaft design and assume that the gear are connected to the shaft without keyways. One important approach of designing a transmission shaft is to use the ASME code. According to this code, the permissible shear stress $\tau_{\max }$ for the shaft without keyways is taken as $30 \%$ yield strength in tension or $18 \%$ of the ultimate tensile strength of the material, whichever is minimum. Therefore,

$\tau_{\max }=0.30$ Syt

$\tau_{\max }=0.18$ Sut (whichever is minimum)

The bending and torsional moments are to be multiplied by factors $\mathrm{Kb}$ and $\mathrm{Kt}$ respectively. To account shock or fatigue in operating condition. The ASME is based on maximum shear stress theory of failure. Therefore equation is modified and rewritten as,

$\tau \max =\frac{16}{\pi \mathrm{d}^{3}} \sqrt{(\mathrm{Kb} \mathrm{Mb})^{2}+(\mathrm{Kt} \mathrm{Mt})^{2}}$

where,

$\mathrm{Kb}=$ combined shock and fatigue factor applied to bending moment.

$\mathrm{Kt}=$ combined shock and fatigue factor applied to tensional moment.

The values of $\mathrm{Kb}$ and $\mathrm{Kt}$ for rotating shaft are given in table.

Table no.1. values of $\mathrm{Kb}$ and $\mathrm{Kt}$

\begin{tabular}{|l|l|l|l|}
\hline Sr no. & Application & $\mathrm{Kb}$ & $\mathrm{Kt}$ \\
\hline 1 & Load gradually applied & 1.5 & 1 \\
\hline 2 & $\begin{array}{l}\text { Load suddenly } \\
\text { applied(minor shock) }\end{array}$ & $1.5-2$ & $1-1.5$ \\
\hline 3 & $\begin{array}{l}\text { Load suddenly applied } \\
\text { (heavy shock) }\end{array}$ & $2-3$ & $1.5-3$ \\
\hline
\end{tabular}

Above equations is used to determine the shaft using the ASME code [9].

$$
d^{3}=\frac{16}{\pi \tau \max } \sqrt{(K b M b)^{2}+(K t M t)^{2}}
$$

Specifications of shaft: Shaft is mounted on two bearings, and one spur gear is mounted on it. The material of shaft is steel FeE $580\left(\mathrm{~S}_{\mathrm{ut}}=770 \& \mathrm{~S}_{\mathrm{yt}}=580 \mathrm{~N} / \mathrm{mm}^{2}\right)$. The factors $\mathrm{Kb}$ and Kt of ASME code are 1.5 and 2 respectively.
1. Permissible shear stress:

$$
0.30 \text { Syt }=0.30 \times 580=174 \mathrm{~N} / \mathrm{mm}^{2}
$$$$
0.18 \text { Sut }=0.18 \times 770=138.6 \mathrm{~N} / \mathrm{mm}^{2}
$$

The lower of two value is $138.6 \mathrm{~N} / \mathrm{mm}^{2}$

3. Shaft diameter:

$$
d=68.59 \mathrm{~mm}
$$

4. Length of shaft:

$$
l=900 \mathrm{~mm}
$$

2) Design of gear: The terminology of gears includes a number of terms peculiar to gears and it forms the basis of gear language. The terminology applied to spur gear is illustrated in fig[10].

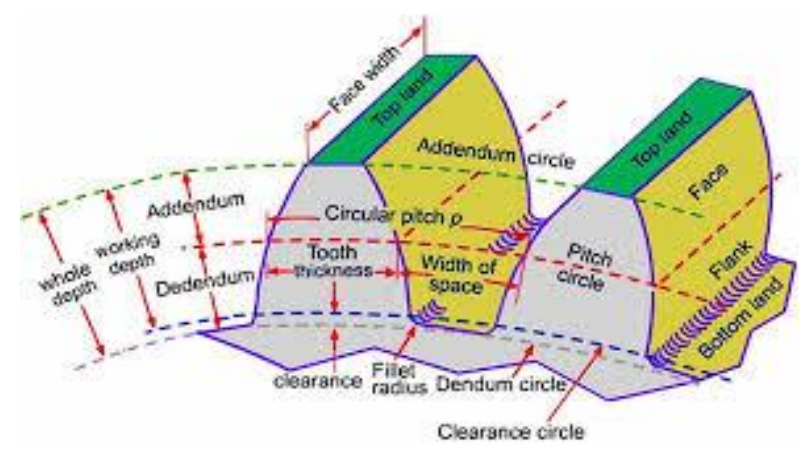

Fig.1. Terminology of gear

Specifications of gear: The pitch circle diameter of gear is $900 \mathrm{~mm}$. Assume module $\mathrm{m}=40$.

1. Number of teeth:

$$
Z=\frac{d^{\prime}}{m}=\frac{900}{40}=22.23 \approx 24 .
$$

2. Addendum(ha):

It is the radial distance between pitch and addendum circle. Addendum indicates height of the tooth above the pitch circle.

$$
h a=m=40 m m
$$

3. Dedendum(hg):

It's the radial distance between pitch dedendum circle. Dedendum indicate the depth of tooth below the pitch circle.

$$
h g=1.25 \times m=50 m m
$$

\section{Clearance(c):}

The clearance is the amount by which the dedendum of the given gear exceed the addendum of its mating tooth.

$$
c=0.25 \times m=10 \mathrm{~mm}
$$

5. Tooth thickness:

$$
1.5708 \times m=62.8 \mathrm{~mm}
$$

6. Working depth(hk):

The working depth is the depth of engagement of two gear teeth that is the sum of their addendums.

$$
h k=2 \times m=80 \mathrm{~mm}
$$


IARJSET

7. Whole depth (h):

It is the total depth of tooth space that is the sum of addendum and dedendum.

$$
h=2.25 \times m=90 \mathrm{~mm}
$$

8. Tooth space:

The width of space between two adjacent teeth measured along the teeth circle.

$$
1.5708 \times m=62.8 \mathrm{~mm}
$$

\section{Fillet radius:}

The radius that connect the root circle to the profile of the tooth.

$$
0.4 \times m=16 \mathrm{~mm}
$$

10. Standard system of the shape of gear tooth.

Select $20^{\circ}$ full depth involutes system for the design of spur gear[10].

\section{IV.EXPERIMENTAL MODAL ANALYSIS}

Experimental modal analysis of a system, deals with determination of natural frequencies, and mode shapes through the vibration testing. In the case of forced vibration, the analysis includes the study of equivalent stress and displacement responses of the systems. The basic ideas involve in model analysis are then structure or machine element such as shaft with gear mounting is excited its response exhibits a critical speed at resonance when the forcing frequency is equal to its natural frequency.

\section{1) Steps to follow:}

a) The geometry of the shaft with gear mounting to be analysed is imported from solid modeller Pro- Engineer in IGES format this is compatible with the ANSYS[11].

b) The element type and materials properties such as Young's modulus and Poisson's ratio are specified.

c) Meshing the three-dimensional model.

d) The boundary conditions and external loads are applied.

e) The solution is generated based on the previous input parameters.

f) Finally, the solution is viewed in a variety of displays.

\section{2) Analysis of Model:}

The Finite Element Analysis (FEA) is a numerical method for solving problems of engineering and mathematical physics \&Useful for problems with complicated geometries, loadings, and material properties where analytical solutions cannot be obtained[11]. In this section we discuss the modelling of shaft with gear, and finite element analysis of shaft with gear using FEA. Finite Element method (FEM) simulates a physical parts behaviour by dividing the geometry into a number of elements of standard shapes, applying constraints. Uses of proper boundary conditions are very important since they strongly affect the results of the finite element analysis. The shaft with gear mounting is modelled in Pro-E. The step file of model is imported in ANSYS workbench. The main objective of this work is to perform the Finite Element Analysis of intermediate shaft using CAE Tools, so as to determine the natural frequency in the shaft. The material properties are demanded in CAE to perform analysis.

2.1 Pre-processing: The constructs a model of the shaft with gear in which the geometry is divided into a number of discrete sub regions, or "elements," connected at discrete points called "nodes." Certain of these nodes will have fixed displacements, and others will have prescribed loads.

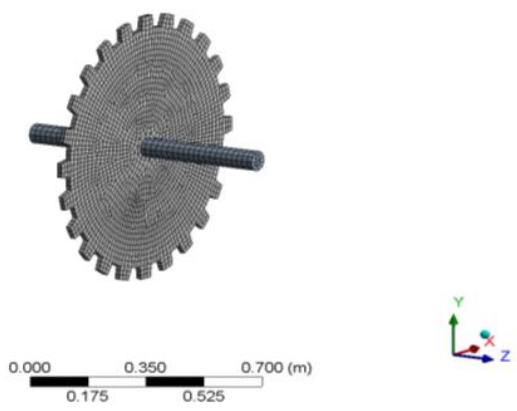

Fig.2. Geometry and meshing of model

2.2 Solution: Solution Part involves declaration of the Analysis type, location of forces and fixation of model.

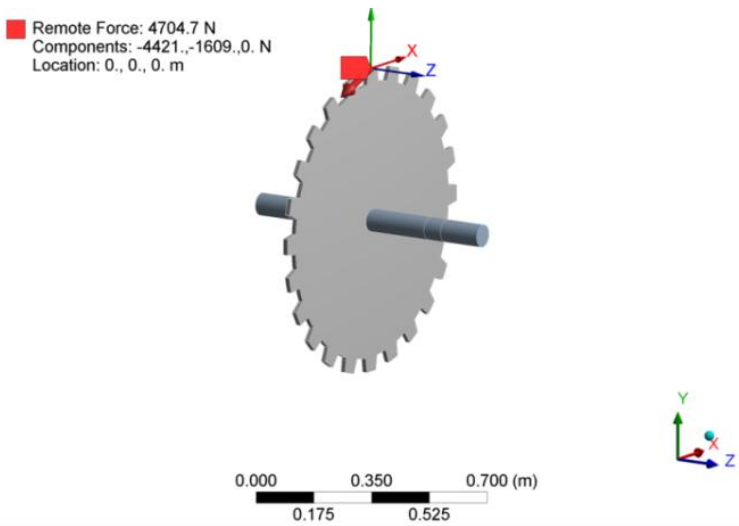

Fig.3. Location of force applied

Fixed Support
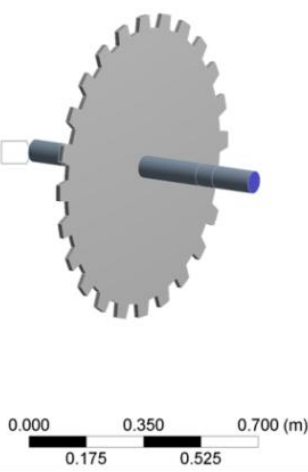

Fig.4. Fixed support 
IAR JSET

International Advanced Research Journal in Science, Engineering and Technology

National Conference on Design, Manufacturing, Energy \& Thermal Engineering (NCDMETE-2017)

AGTI's Dr. Daulatrao Aher College Engineering, Vidyanagar Extension, Karad

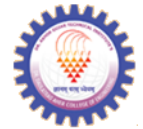

Vol. 4, Special Issue 1, January 2017

2.3 Post Processing: The post processing stage involves Hence with the help of ANSYS software we find out the viewing of data files generated by the software during the total deformation, equivalent stress which is response for solution phase.

noise and vibration of shaft with gear mounting.

\subsubsection{Result obtain from ANSYS:}
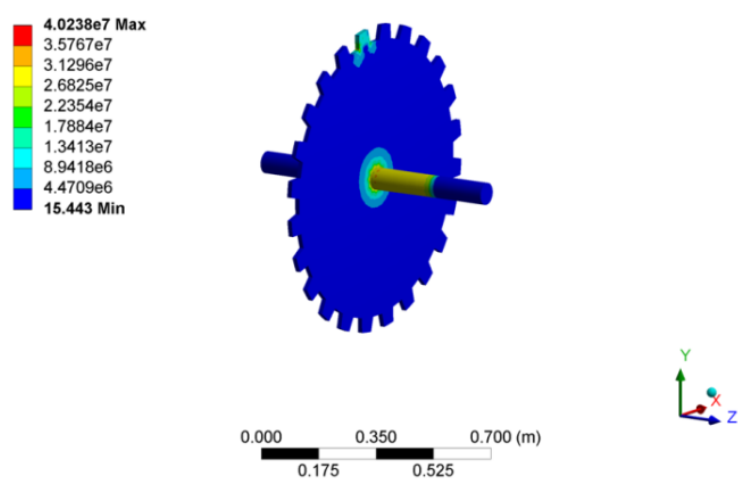

Fig.5. Equivalent Von-Misses Stress (in Pa)
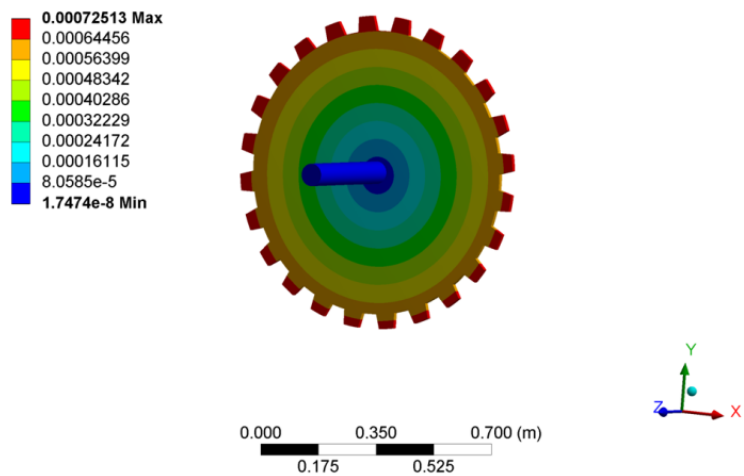

Fig.6. Total deformation (in $\mathrm{m}$ )

\section{RESULTS AND DISCUSSION}

Automobile Shaft with gear mountings undergoes noise and vibration frequently. The maximum voin mises stress generated is $4.023 \times 10^{7} \mathrm{~N} / \mathrm{m}^{2}$ and the maximum deformation generated is $7.2 \times 10^{-4} \mathrm{~m}$. The results obtained are within limits and will have minimum effect on the working condition of the shaft and gear. The material used and the design developed for the required force is valid for the automobile shaft and gear mountings.

\section{VI.CONCLUSION}

The finite element method (FEM) is most widely for Natural frequency analysis of machine elements using the ANSYS software. The shaft with gear is modelled in PRO-E and analysed in ANSYS for its natural frequency. The development of finite element analysis model of the shaft with gear mounting to simulate the voin-misses stress calculation and total deformation calculation is play more significant role in the design. FEM methods for calculation of natural frequencies of shaft with gear are described..

\section{ACKNOWLEDGMENT}

The authors would like to express sincere gratitude to Department of Mechanical Engineering, Dr. Daulatrao Aher College Engineering, Karad, Satara, India for their help and support.

\section{REFERENCES}

[1] "Vibration Analysis for Gearbox Casing Using Finite Element Analysis", Mr.vijaykumar, Mr.shivaraju, Mr.srikanth, The International Journal Of Engineering And Science (IJES), Volume 3,Issu 2, Pages 18 - 36, ISSN (e): 2319 - 1813 ISSN (p): $2319-$ $1805,2014$.

[2] "Design and Stress, Strain Analysis of Polyoxymethylene Spur Gear For Sugarcane Juice Machine", S.Arunkuma, S.Easwaran, B.Murugan, B.Prathess, K.Vediyappan,International Journal Of Research In Aeronautical And Mechanical Engineering Issn (Online): 2321-3051,April 2015.

[3] "Design, Analysis and Testing of shaft mounted speed reducer for coil winding machine", Kate-Deshmukh N.S., Gaikwad M.U, International Research Journal of Engineering and Technology (IRJET), e-ISSN: 2395 -0056, p-ISSN: 2395-0072, Volume: 03 Issue: 01 | Jan-2016.

[4] "Modal Analysis of Intermediate Shaft Used In Automobile Gear Box".Mr.Shekhar Dive, Prof.PrashantKarajagi, International Journal Of Engineering Research \& Technology (IJERT) IJERTIJERT ISSN: 2278-0181 IJERTV3IS051036 Www.Ijert.Org Vol. 3 Issue 5, May - 2014.

[5] "FE Analysis of hollow propeller shaft using different composite material - A Review study", Nimesh A. Patel, Pradip M. Patel, Prof. A. B. Patel, International Journal Of Scientific Research (IJSR), Volume : 2 | Issue : 5 | May 2013, ISSN No 2277 - 8179, May 2013.

[6] "Modal Analysis Of Spur Gear To Determine The Natural Frequencies And It's Effect Over The Geometry Of The Gear", Nilofar Hajikhan Pathan, Dr. V.P. Singh, Swapnil S. Kulkarni, International Journal of Advanced Engineering Research and Studies, E-ISSN2249-8974, Int. J. Adv. Engg. Res. Studies/III/III/April-June,2014/76-78, 2014.

[7] "Gear Noise And Vibration", Mats Akerblom, Volvo Construction Equipment Components AB, SE-631 85 Eskilstuna, Sweden, mats.akerblom@volvo.com.

[8] "Analysis of Carbon/Epoxy Composite Drive Shaft for Automotive Application", Pandurang V Chopde, Prof. R.B.Barjibhe, International Journal of Latest Trends in Engineering and Technology (IJLTET), ISSN: 2278-621X, Vol. 5 Issue 1 January 2015.

[9] "Design of Machine Elements", V. B. Bhandari. Tata Mcgraw Hill Book Company, 2010.

[10] "Machine Design", R. S. Khurmi and J.K Gupta,Tata Mcgraw Hill Book Company, 2005.

[11] "Finit Element Analysis- Theory and Application with ANSYS", Sawed Moveni, Prentice-Hall of India, $2^{\text {nd }}$ Edition. 